\title{
COVID 19 Y SU IMPACTO EN LA APLICACIÓN DE LAS NORMAS INTERNACIONALES DE INFORMACIÓN FINANCIERA (NIIF)
}

\author{
AUTORES: Eddy Joao Chillogallo Zambrano ${ }^{1}$ \\ Dewis Edwin Álvarez Pincay ${ }^{2}$ \\ Zoila Mariana Delgado Gutiérrez ${ }^{3}$
}

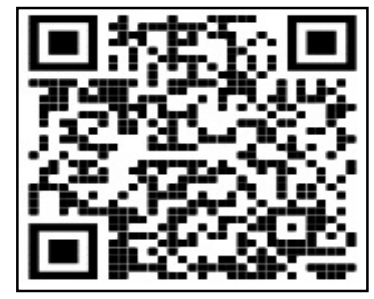

DIRECCIÓN PARA CORRESPONDENCIA: chillogallo-eddy1513@unesum.edu.ec

Fecha de recepción: 03/10/2020

Fecha de aceptación: 28/12/2020

\section{RESUMEN}

Esta investigación tiene como objetivo conocer los impactos que ha tenido el coronavirus en el tratamiento contable conforme NIIF, ante un escenario de gran incertidumbre y dudas significativas, es sumamente importante cumplir con las características cualitativas de las NIIF en los estados financieros, que son brindar información relevante y fiable para los tomadores de decisiones, los cuales utilizan como base la información financiera para tomar medidas acertadas conforme la eficiencia, eficacia de las operaciones y la salud económica de la entidad. Mediante este estudio se pudo conocer que las normas NIC 1, NIC 2, NIC 10, NIIF 9, NIIF 16 marcan una mayor relevancia, debido a que se han visto involucradas en el tratamiento contable e información a revelar en los estados financieros frente. Por lo tanto, la hipótesis de negocio en marcha, deterioro de inventarios, deterioro de activos financieros, hechos a revelar después del periodo sobre el que se informa, contratos de arrendamientos proporcionan información relevante al momento de realizar la toma de decisiones, además de ayudar a predecir ciertos eventos que puedan afectar la salud económica y financiera de una entidad. La metodología utilizada en esta investigación fue de tipo documental, apoyándose por las técnicas de resumen y fichaje para la recolección de datos.

PALABRAS CLAVE: Escenario de incertidumbre; estados financieros; características cualitativas; negocio en marcha.

\footnotetext{
${ }^{1}$ Estudiante de la Carrera de Contabilidad y Auditoría de la Universidad Estatal del Sur de Manabí. Jipijapa, Manabí, Ecuador. E-mail: chillogallo-eddy1513@unesum.edu.ec, ORCID ID: https://orcid.org/0000-0002-4181-7581

32 licenciado en Contaduría y Auditoría, Máster en Dirección Estratégica. Docente Investigador Auxiliar 1 SENESCYT. Docente Titular Principal., Responsable Comisión de Vinculación Carrera de Contabilidad y Auditoría. Universidad Estatal del Sur de Manabí. Jipijapa, Manabí, Ecuador. Email: dewis.alvarez@unesum.edu.ec

${ }^{3}$ Economista, Máster en Contabilidad y Auditoría. Docente Contratada. Universidad Estatal del Sur de Manabí. Jipijapa, Manabí, Ecuador. Email: zoila.delgado@unesum.edu.ec
}

(C) Universidad Estatal del Sur de Manabí. Jipijapa, Ecuador. 
Eddy Joao Chillogallo, Dewis Edwin Álvarez, Zoila Mariana Delgado

\title{
COVID 19 AND ITS IMPACT ON THE APPLICATION OF INTERNATIONAL FINANCIAL INFORMATION STANDARDS (IFRS)
}

\begin{abstract}
This research aims to know the impacts that the coronavirus has had on the accounting treatment in accordance with IFRS, in a scenario of great uncertainty and significant doubts, it is extremely important to comply with the qualitative characteristics of IFRS in the financial statements, which are to provide information relevant and reliable for decision makers, who use financial information as a basis to take appropriate measures according to the efficiency, effectiveness of operations and the economic health of the entity. Through this study it was possible to know that the standards IAS 1, IAS 2, IAS 10, IFRS 9, IFRS 16 mark a greater relevance, because they have been involved in the accounting treatment and information to be disclosed in the financial statements. Therefore, the going concern assumption, inventory impairment, financial asset impairment, disclosures after the reporting period, lease contracts provide relevant information when making decisions, in addition to helping to predict certain events that may affect the economic and financial health of an entity. The methodology used in this research was of a documentary type, supported by summary and recording techniques for data collection.
\end{abstract}

KEYWORDS: Uncertainty scenario, financial statements, qualitative characteristics, going concern.

\section{INTRODUCCIÓN}

El desarrollo de una nueva pandemia, conocida como coronavirus o COVID-19, ha generado a nivel mundial gran incertidumbre en los diferentes niveles sociales, políticos y económicos, provocando no solo la muerte de un sinnúmero de personas, sino que también ha afectado la economía de los países y por ende ha generado gran incertidumbre en muchas empresas productoras de bienes y servicios en cuanto al impacto que se puede incurrir en los resultados, patrimonio y situación financiera, por lo que el objeto de esta investigación es conocer los impactos que ha tenido el coronavirus en el tratamiento contable y la presentación de información financiera conforme las NIIF.

La organización mundial de la salud (OMS) en su página web expresa que el coronavirus se puede contagiar de los animales a las personas, mediante una transmisión zoonótica, causando fiebre y síntomas respiratorios y en casos más graves puede causar hasta neumonía, síndrome respiratorio agudo severo, insuficiencia renal, e incluso hasta la muerte (OMS, 2020).

Por estas razones, la OMS ha hecho énfasis en la recomendación de que las personas eviten el contacto con otras, remarcando que se queden en casa con la finalidad de contener al virus. Sin embargo, estas recomendaciones afectan al sector económico, por ende, empresarial, donde muchas empresas han reducido y hasta casi detenido por completo su producción, paralizando así las transacciones comerciales, conllevando que muchas empresas tomen medidas drásticas con el propósito de poder sobrevivir en un mercado post COVID 19, muchas de las medidas tomadas tienen un alto impacto en la elaboración y presentación de los estados financieros.

Como ya se mencionó, la elaboración y presentación de Estados financieros se ha visto afectados por esta pandemia, debido a que los estados financieros bajo NIIF deben cumplir con las características cualitativas principales, como lo son la representación fiel y relevancia en la 
información, por lo que, muchos de los riesgos generados por el Coronavirus deben ser revelados en el juego de estados financieros. En las notas explicativas se debe revelar los riesgos financieros significativos, además, los cambios que pueden ocurrir en el tratamiento contable de contratos de arrendamientos, instrumentos financieros, deterioro de activos financieros y no financieros, por citar algunos ejemplos que pueden afectar en la toma de decisiones.

En este contexto Pinto (2020) indica que el entorno económico de una entidad puede verse afectado, en el caso de los inventarios, dependiendo de su naturaleza, estos pudieron haberse vencido, pasado de moda, perdido valor en el mercado, con el consecuente deterior de valor con relación al importe que estaba registrado en los libros. No obstante, las normas contables no cambian, sino que la persona encargada de la preparación de información financiera debe poner especial cuidado y hacer uso correcto de su criterio profesional.

\section{DESARROLLO}

Mediante el análisis e interpretación de las NIIF, se logró identificar algunas NIIF que podrían sufrir afectaciones en los procedimientos contables, destacando los descritos a continuación:

\section{Hechos ocurridos después del periodo sobre el que se informa}

Los hechos ocurridos después del periodo sobre el que se informa, también llamado eventos subsecuentes, están normados por la NIC 10, la cual establece los criterios contables, parámetros, lineamientos sobre el tema de los hechos pasados, ayudando así a la toma de decisiones entre el lapso del cierre de los Estados Financieros que por lo general es el 31 de diciembre de un determinado año hasta la fecha de autorización de los estados financieros.

La NIC 10, Establece que los hechos ocurridos después del periodo sobre el que se informa son "Todos aquellos eventos, ya sean favorables o desfavorables, que se han producido entre el final del periodo sobre el que se informa y la fecha de autorización de los estados financieros para su publicación” (IASB, Normas NIIF ilustradas, 2020, pág. A1064). Es decir, esta normativa técnica brinda un tiempo extra para hacer cualquier reajuste o perfeccionamiento de la información financiera antes de que esta sea publicada, ya sea en temas de ajustes contables o revelación en notas, para que los estados financieros brinden información útil a los usuarios de estados financieros.

En ese contexto, Fowler (2016) indica que las entidades deberían informar sobre los hechos ocurridos entre la fecha que se refieren los Estados Financieros y la autorización de estos para su publicación que no correspondan considerar para efectuar las mediciones contables de los activos y los pasivos a la fecha de ellos cuando afecte significativamente la estructura patrimonial del emisor de estados financieros o introduzcan incertidumbre sobre los resultados futuros que afecten las producciones que podrían efectuase sobre ellos

En la vida práctica muchas empresas no cierran en tiempo real el 31 de diciembre, debido a que existe mucha información por corroborar y confirmar, además, muchas empresas deben pasar por un proceso de auditoría externa, lo que genera que exista una brecha de tiempo hasta llegar a la 
fecha de autorización de los estados financieros para su publicación. Todo lo acontecido en esa brecha de tiempo son los hechos ocurridos después del periodo que se informa.

En Ecuador, la Ley de Compañías en el artículo 20, determina que las compañías constituidas en Ecuador, sujetas a la vigilancia y control de la Superintendencia de Compañías, deben enviar sus estados financieros en el primer cuatrimestre de cada año, es decir, hasta el 30 de abril, y la aprobación de los mismos dependerá de las políticas de cada institución. Por lo tanto, en la brecha de tiempo generada pueden ocurrir diferentes eventos subsecuentes que afecten de manera significativa el curso de la institución.

En ese procedimiento, pueden existir dos tipos de hechos, uno de ellos son los hechos ocurridos después del periodo que se informan e impliquen ajuste a partidas contables, de acuerdo a la norma esto ocurre porque los acontecimientos que se hacen presente luego del 31 de diciembre ya muestran evidencia de condiciones o situaciones preexistentes para la entidad, es decir, esta información ya corrobora a eventos que estaba sucediendo a finales del año anterior.

Sin embargo, hay hechos que no implican ajustes contables a la fecha de presentación, es decir, son hechos ocurridos después del periodo que se informa pero que no implican ajuste, conforme a la norma, si estos eventos son significativos y no implican ajustes deben ser revelados en las notas a los estados financieros, con la finalidad de brindar información útil para los tomadores de decisiones. Una de las principales razones de que estos hechos no impliquen ajuste, es que son nuevos eventos o acontecimientos que propiamente han acaecidos en el año subsiguiente, y que no brindan ninguna evidencia de situaciones ya existentes o de condiciones preexistentes para la entidad al 31 de diciembre.

Para citar un claro ejemplo de las situaciones ocurridas con el COVID 19 y esta norma, se puede tomar a las empresas domiciliadas en Wuhan, donde a finales de diciembre del 2019 empieza a surgir el brote de este virus, el cual recién en marzo del 2020 fue declarado como pandemia, surgiendo aquí varias incógnitas sobre si la aparición de este virus implica ajuste o no, debido a que el virus surgió a finales del 2019, no obstante, los hechos destacados recién se presentan en el año 2020.

Todo esto tiene varias aristas de analizar, entre las que se tiene el lugar donde está domiciliada la entidad y en si cual es el hecho ocurrido después del periodo sobre el que se informa que afecta a la entidad, siendo el objeto de análisis si es en sí el brote del virus que afecta a la entidad, o si son las medidas adoptadas por el gobierno para evitar la propagación del virus. Para los países que las medidas de gobierno fueron impuestas en el 2020 como el aislamiento social, toque de queda, son hechos ocurridos después del periodo que se informa que no implican ajustes, por el contrario, si son entidades que sus operaciones están en Wuhan y se vieron afectadas directamente con el brote del virus, queda a juicio profesional que si implique ajuste contable.

No obstante, a ser hechos significativos y materiales amerita una revelación en notas en los estados financieros sobre estas incertidumbres, con la finalidad de informar a los accionistas, inversores, socios sobre esta situación para que tomen medidas precavidas sobre las cifras que se estiman en los estados financieros. Todo este ambiente de incertidumbre genera que no sea tan factible una estimación de todos los impactos generados, al no poder estimar de manera fiable estos impactos, de igual manera se debe revelar en las notas a los estados financieros. 
Por lo contrario, todos estos hechos ocurridos después del periodo sobre el que se informa si generarán ajuste para los estados del año 2020, además, existen entidades como los mercados de valores, o regulados que presentan estados financieros intermedios, lo que implica el uso del juicio profesional en la aplicación de los ajustes contables

\section{Hipótesis de negocio en marcha}

Todo estado financiero bajo NIIF parte de la presunción de que la empresa va a seguir operando en un futuro previsible, de acuerdo con la NIC 1 Presentación de estados financieros:

Una entidad elaborar los estados financieros bajo la hipótesis de negocio en marcha, a menos que se tenga pensado liquidar dicha entidad o cesar en su actividad, o bien no exista otra alternativa más realista que proceder de una de estas formas (IASB, Normas NIIF ilustradas, 2020, pág. A962).

Para Correa y Castillo "un negocio en marcha, quiere decir que el negocio tiene finalidad de lucro y que para generarlo la entidad permanecerá en el tiempo" (Correa \& Castillo, 2016), en otras palabras, que la entidad o empresa tenga planes futuros de seguir operando y que no tenga en consideración cerrar o liquidar sus operaciones.

Sin embargo, ante esta situación de incertidumbre, de dudas significativas o de volatilidad esta hipótesis es puesta en cuestionamiento en muchas empresas, entonces, hay que evaluar la capacidad que tiene una entidad para seguir laborando, por lo tanto, la entidad debe formularse estas preguntas claves: ¿es la entidad financieramente fuerte? ¿Son sus activos de alta calidad? ¿La entidad podrá subsistir los próximos 12 meses? ¿Podrá encontrar fuentes alternativas de financiamiento para su negocio?

Haciendo este análisis en los diferentes giro del negocio, se pueden llegar a dos conclusiones, la primera que se determine que la entidad si es un negocio en marcha, no obstante se debería revelar en las notas que esta evaluación fue realizada en un escenario de incertidumbre y de dudas significativas, y la otra conclusión es que se determina que la entidad no es un negocio en marcha, de acuerdo con la norma internacional se debe revelar que la entidad no es un negocio en marcha, junto a la hipótesis sobre las que han sido elaborados y las razones por que la entidad no se considera un negocio en marcha, además los estados financieros se deben preparar bajo una base de presentación diferente que represente de manera adecuada la información útil y relevante para los lectores de los estados financieros, aunque las NIIF no especifican bajo que normativa elaborar estos los estados financieros, dejando a juicio profesional, pero a manera de preferencia se pueden tomar los principios generalmente aceptados o tomar como referencias normas similares a las NIIF como las US GAAP, siempre y cuando represente fielmente la situación de la entidad y realmente brinda información útil.

Por otra parte, aunque existan entidades que determinen que si son un negocio en marcha pueden existir factores que afecte su continuidad, tomando como referencia, la declaración por parte de la OMS al COVID 19 como pandemia, los gobiernos alrededor del mundo adoptaron medidas para prevenir la proliferación de este virus, limitando la movilidad de personas, afectando así las diferentes actividades económicas, aunque una entidad espere continuar con sus operaciones 
Eddy Joao Chillogallo, Dewis Edwin Álvarez, Zoila Mariana Delgado

predecibles, pueden existir factores que pongan en riesgo su continuidad, por lo tanto, aunque hayan llegado a la conclusión de ser un negocio en marcha y no tengan problemas significativos, puede que sus clientes si posean problemas, afectando así a la entidad, debido a que una empresa sin sus clientes no podrá funcionar a largo plazo

\section{Deterioro de los activos Financieros}

Para Parrales y Castillo "la aplicación de la NIIF 9 ayuda a simplificar y mejorar la contabilización de los instrumentos financieros reduciendo las asimetrías contables que se originarían debido al modelo de negocio. Además, permitirá clasificar las inversiones en instrumentos financieros, las cuales en ciertos casos podrían ser sustanciales” (Parrales \& Castillo, 2018, pág. 18).

Hasta la fecha existen dos enfoques, el de la pérdida incurrida vigente solo en NIIF para PYMES, el que sostiene en que se debe proceder a castigar los activos financieros cuando se presente e información observable, evidencia objetiva. En escenario actual, donde existen empresas que están quebrando, se puede empezar a disparar estas pérdidas incurridas, en activos comerciales financieros como cuentas comerciales por cobrar.

Por otro lado, se tienen las pérdidas esperadas, el cual está vigente en NIIF completas, contemplando que se deben registrar pérdidas incurridas cuando sucedan los hechos, sino que también se deben in registrando pérdidas esperadas en base a información futura, con la finalidad de esclarecer ciertas dudas el IASB ha publicado un documento NIIF 9- instrumentos financieros y el COVID 19, el cual sirve de soporte para la aplicación consistente de esta norma. La NIIF 9 establece dos enfoques para realizar el deterioro de estos activos, el enfoque general que pasa por tres etapas el cual es más aplicable a entidades que tienen carteras de crédito, préstamos por cobrar, entre otros instrumentos que son más principalmente muy propios de entidades financieras y aseguradoras, entonces cuando se maneja el enfoque general, en la etapa 1 tan pronto se genera un activo financiero las pérdidas crediticias esperadas en los próximos doce meses se analiza y se reconoce en resultados a través de una cuenta correctora, es decir, tener una pérdida que se pueda dar en ese instrumento, se la multiplica por la probabilidad de que se produzca esta pérdida dentro de los doce meses siguientes. Al pasar de la etapa 1 a la etapa 2, se reconoce perdidas crediticias esperadas durante todo el tiempo de vida del instrumento, ya no solo por los doce meses, por lo que en la etapa 2 se produce mayores pérdidas. La etapa 3, se da en el caso de que siga subiendo ese riesgo de crédito hasta tal punto de que la perdida esperada se transforme en perdida incurrida, los activos ya se analizan más de manera individual.

Aunque la norma no proporcione metodologías específicas para analizar si los riesgos de activos financieros han aumentado significativamente, se debe utilizar el buen juicio profesional. Sin embargo, el IASB (2020) en su documento que hace referencia a las NIIF y el COBIT 19, menciona que no se debe asumir de manera general que para todos los clientes se ha aumentado el riesgo de crédito, si bien muchas entidades financieras han otorgado meses de gracias y demás estrategias que den como resultado aplazamiento de los pagos sin recargos, eso no necesariamente señala que los clientes que deben estén en una situación crítica o de crisis significativa que no pueda cumplir con sus obligaciones, entonces lo que recomienda el IASB es que se deba analizar la situación de las situaciones particulares de los diferentes tipos de instrumentos y los diferentes tipos de clientes, recalcando que no se aplique el modelo de perdidas esperadas de forma mecánica. 
Por otra parte, las empresas comerciales, industriales que tienen cuentas comerciales por cobrar o arrendamientos por cobrar o activos del contrato, de acuerdo a la NIIF 9 les permite utilizar de una forma simplificada una matriz de pérdidas crediticias esperadas.

\section{Arrendamientos}

Para la firma internacional Deloitte (2016) el objetivo que tiene la NIIF 16 es ayudar a los preparadores y usuarios de la información financiera respecto a la falta de comparabilidad entre la normativa y resolver algunas limitaciones que se tenía con la ya derogada NIC 17, en cuanto a la información acerca de arrendamientos operativos y la exposición que tienen las empresas por este tipo de contratos. El IASB define a los arrendamientos como "un contrato, que transmite el derecho a usar un activo (activo subyacente) por un periodo de tiempo a cambio de una contraprestación” (IASB, Normas NIIF ilustradas, 2020, pág. A1066)

Conociendo que es un contrato, y que a partir de los hechos ocurridos por el COBIT19, muchas compañías arrendadoras y arrendatarias negociaran concesiones, ya sea en días de gracias, aplazamientos en los pagos, rebajas en cuotas, cambiando así los pagos por arrendamientos, estos cambios se pueden producir de forma directa cuando se realizan cambios a los contratos de arrendamientos, e indirecta si son imposiciones de los gobiernos, existiendo alguna ley o reglamento aplicable frente a estas situaciones de fuerza mayor, en cualquiera de los dos casos, para la NIIF 16 tienen igual trato, son cambios del pago en el arrendamiento.

El tratamiento contable, va a depender si esos cambios en los pagos califican como modificación del contrato, entendido como modificación del contrato cuando haya cambios en el alcance, es decir cuando se tenga derecho a utilizar más o menos activos, o tener extensión o acortamiento del plazo contractual; otro aspecto es realizar cambios de pago por el arrendamiento, que en esencia realicen cambios en los términos y condiciones originales del contrato

En el caso de que, si haya una modificación del contrato, se deberá considerar si es arrendatario se deberá poner a consideración los párrafos del 44 al 46 de la NIIF 16 y en el caso de ser arrendador se deberá tomar en cuenta los párrafos 79 al 80 u 87 de la misma norma (IASB, Normas NIIF ilustradas, 2020)

Además, el IASB ha emitido una enmienda NIIF 16 sobre arrendamientos para ayudar a los arrendatarios a contabilizar las reducciones de alquiler relacionadas, en su párrafo 46A y 46B determina que:

46A Como solución práctica, un arrendatario puede optar por no evaluar si la reducción del alquiler relacionada con el COVID-19 (véase el párrafo 46B) es una modificación del arrendamiento. Un arrendatario que realiza esta elección contabilizará los cambios en los pagos por arrendamiento procedentes de las reducciones del alquiler relacionadas con el covid-19 de la misma forma que contabilizaría el cambio aplicando esta Norma si dicho cambio no fuera una modificación del arrendamiento

46B La solución práctica del párrafo 46A se aplica solo a las reducciones del alquiler que ocurran como consecuencia directa de la pandemia COVID-19 y si se cumplen las siguientes condiciones:

(C) Universidad Estatal del Sur de Manabí. Jipijapa, Ecuador. 
Eddy Joao Chillogallo, Dewis Edwin Álvarez, Zoila Mariana Delgado

(a) el cambio en los pagos por arrendamiento da lugar a la revisión de la contraprestación por el arrendamiento que es sustancialmente la misma, o menor, que la contraprestación por el arrendamiento inmediata anterior al cambio;

(b) cualquier reducción en los pagos por arrendamiento afecta solo los pagos originalmente debidos al, o antes del, 30 de junio de 2021 (por ejemplo, una reducción del alquiler cumpliría esta condición si da lugar a una reducción de los pagos por arrendamiento al, o antes del, 30 de junio de 2021 y a un incremento en los pagos por arrendamiento que se prolongue más allá del 30 de junio de 2021); y

(c) no existe un cambio sustancial en los otros términos y condiciones del arrendamiento. (IASB, Covid-19 Related rent concessions ammendament to IFRS 16, 2020)

Esta enmienda que entra en vigencia el 1 de junio del 2020, fue emitida para dar ciertas facilidades a los arrendatarios a contabilizar las concesiones relacionadas al COVID 19, eximiendo que los arrendatarios tengan que considerar contratos de arrendamiento individuales para determinar si las concesiones de alquiler son modificaciones de arrendamiento y les permite a los arrendatarios contabilizar tales concesiones de alquiler como si no fueran modificaciones de arrendamiento. Se aplica a las concesiones de alquiler relacionadas con el COVID-19 que reducen los pagos de arrendamiento vencidos el 30 de junio de 2021 o antes, además, un arrendatario que aplique la solución práctica del párrafo 46A deberá revelar este hecho.

Inventarios

Para Ortega, Palma y Nuñez los "inventarios incluyen tanto la materia prima, productos en proceso y productos terminados, mercancías destinadas para la venta, materiales y repuestos para ser consumidos en la producción de bienes o usados en la prestación de un servicio” (2019, pág. 119).

Los inventarios son otros de los factores afectados por esta pandemia, debido a que muchos de ellos sufrirán deterioro. El deterioro de inventario según Perez (2014) se da cuando una parte del inventario se desperdicia durante cada lapso de tiempo. Por lo tanto, la NIC 2 que trata sobre los inventarios determina que en cada fecha de presentación deberán ser medidos al valor menor entre el costo y el Valor Neto Realizable (VNR), siendo el costo lo que significó para la empresa comprar o producir el inventario, mientras que el VNR es el precio de venta estimado menos los costos estimados de terminación y venta.

Los inventarios con el pasar del tiempo se pueden desvalorizar por diferentes razones, dependiendo del giro del negocio y tipo de inventario, obsolescencia tecnológica, cambios y gustos en la preferencia de los consumidores, la caducidad que se aproxime. Ante la situación del COVID 19 se puede dar como ejemplo que, muchas empresas han paralizado sus funciones, afectando a los inventarios debido a que no se están realizando ventas y por ende los inventarios no están rotando y muchos de los mismos tienen caducidad, de tal manera que cuando la empresa vuelva a reactivar sus actividades y la fecha de caducidad de inventarios esté próxima se deberán tomar acciones de marketing para que estos inventarios sean vendidos de una manera oportuna, donde muchas de las empresas van a intentar vender hasta por debajo del costo, sacrificando parte del costo a perder la totalidad de los costos.

Entonces, la empresa desde el momento que va a vender por debajo del costo, debe rebajar el precio de los inventarios y reconocer la pérdida por deterioro, no se debe esperar que se haya

162 UNESUM-Ciencias. Publicación cuatrimestral. Vol. 5, No. 1 (Enero-Abril), Año 2021 
vendido por debajo del costo para reconocer la pérdida, porque ya los hechos estarían dados y la alta gerencia o proveedores de capital no van a poder realizar una toma de decisiones oportuna, por lo tanto, la norma establece que se debe informar previamente que estos inventarios se van a vender por debajo del costo, para que así los usuarios de los estados financieros conozcan de una manera oportunidad y cuantificada el valor que van a tener por pérdidas y poder tomar medidas al respecto.

\section{Materiales y métodos}

En este estudio se utilizó el tipo de investigación documental, donde cada actividad a ejecutar partió de la revisión de documentos y reportes bibliográficos, los que servirán como fuente para describir cada elemento de las variables en curso. Esto contribuye a analizar la teoría de manera descriptiva, llevando a los investigadores a profundizar en la indagación, con la finalidad de exponer sus criterios de interpretación en función a los planteamientos establecidos en cada uno de los objetivos propuestos para su desarrollo.

Los estudios documentales presentan particularidades de apoyo bibliográfico, conduciendo a la introducción de técnicas que ayuden a facilitar la interpretación, por lo que en esta investigación se utilizaron técnicas que corresponden al trabajo intelectual, recurriendo a la consulta de fuentes, entre las que se encuentran la técnica del resumen y el fichaje.

\section{Resultados y discusión}

Muchas de las empresas han tenido inconvenientes a raíz de la propagación de este virus, provocando un impacto significativo en ellas, conforme las características cualitativas de las NIIF relevancia y fiabilidad, la presentación de estados financieros se puede convertir en un verdadero dolor de cabeza para muchas entidades que dependen de esta información, ya que representaran la información base para que los tomadores de decisiones lo hagan de la manera más acertada posible, por lo tanto, la fiabilidad y relevancia de los estados financieros va a depender de la realización del proceso contable conforme a NIIF. En la investigación realizada por Barbei, González y Tiberi (2020) expresan que ninguna de las entidades encuestadas hacen referencia o mencionan al COVID-19 ni sus efectos en los estados financieros, de igual manera, que ninguna de las empresas hacen mención a este virus en ninguna de las notas que constituyen la información complementaria y tampoco en el contenido de los estados financieros, teniendo como consecuencia limitaciones a la utilidad de la información contable para la toma de decisiones.

\section{CONCLUSIONES}

Es muy necesario que las entidades realicen una contabilidad alineada a las NIIF, ante la situación del COVID-19 se debe seguir presentando una información relevante y fiable que sirva de sustento para la toma de decisiones, por lo tanto, se debe dar a conocer los riesgos significativos y ciertos escenarios de incertidumbre que pueda estar atravesando la entidad aun cuando ocurran después del periodo sobre el que se informa, identificando si son eventos que 
Eddy Joao Chillogallo, Dewis Edwin Álvarez, Zoila Mariana Delgado

impliquen ajuste o no y así realizar el tratamiento contable correspondiente, conforme la norma hechos ocurridos después del periodo sobre el que se informa (NIC 10), además, se debe revelar si la entidad sigue funcionando bajo la hipótesis de negocio en marcha (NIC 1), así mismo debe realizar una revaluación de los inventarios que pudieron haber sufrido un deterioro producto de la para de actividades(NIC 2), algo similar ocurre con el deterioro de activos financieros, ante la creciente incertidumbre de los riesgos, se debe realizar una revaluación a las cuentas comerciales por cobrar, y así poder castigar los activos financieros por pérdidas esperadas y pérdidas ocurridas ((NIIF 9), en cambio con los contratos de arrendamiento se debe realizar un análisis a las concesiones y determinar si existe o no un cambio o modificación en las condiciones del contrato y así darle el tratamiento contable respectivo (NIIF 16).

\section{REFERENCIAS BIBLIOGRÁFICAS}

Barbei, A., González, P., \& Tiberi, S. (Abril de 2020). ¿Qué dicen las empresas sobre el COVD-19? Obtenido de CECIN: https://www.econo.unlp.edu.ar/frontend/media/66/20266/d08b7f54db8fdd11a3f526c1a3ae1446.pdf

Correa, C., \& Castillo, B. (2016). Implementacion de NIIF para PYMES. Obtenido de Universidad de la Salle: https://ciencia.lasalle.edu.co/cgi/viewcontent.cgi?article=1543\&context=contaduria_publica

Deloitte. (febrero de 2016). NIIF 16 Arrendamientos: Lo que hay que saber sobre como van a cambiar los arrendamientos. Obtenido https://www2.deloitte.com/content/dam/Deloitte/es/Documents/auditoria/Deloitte_ES_A

Fowler, N. (2016). Contabilidad Superior (Vol. $7^{\circ}$ Edición). Buenos Aires: La Ley.

IASB. (mayo de 2020). Covid-19 Related rent concessions ammendament to IFRS 16. Obtenido de IFRS Org: //cdn.ifrs.org/-/media/project/ifrs-16-covid-19/covid-19-related-rent-concessions-amendment-to-ifrs16.pdf?la=en\&fbclid=IwAR1iVY8fpUVpmGcYGs817u9nMitRphnHLvdjLZtVbhXyXsT6iZAAwVXvpck

IASB. (27 de marzo de 2020). IFRS 9 and COVID-19. Obtenido de IFRS Org: https://cdn.ifrs.org//media/feature/supporting-implementation/ifrs-9/ifrs-9-ecl-and-coronavirus.pdf?la=en

IASB. (2020). Normas NIIF ilustradas. Inglaterra.

OMS. (2020). Coronavirus. Obtenido de Organizacion Mundial de la Salud: https://www.who.int/es/healthtopics/coronavirus

Ortega, R., Palma, A., \& Nuñez, E. (2019). Aplicacion de la NIC 2 en la valoracion de inventarios de las empresas hoteleras del Canton Quevedo. Revista de Agrupacion Joven Iberoamericana de Contabilidad y Administracion, 116-125.

Parrales, C., \& Castillo, F. (2018). Analisis de NIIF 9- Instrumentos Financieros desde una perspectiva industrial. $\begin{array}{lllll}\text { Contabilidad } & y & \text { Negocios, } & \text { Obtenido }\end{array}$ https://www.redalyc.org/jatsRepo/2816/281658256005/html/index.html

Perez, F. (2014). Modelo de inventarios con productos perecederos: revision de literatura. Articulo de Revision, 9-40. Obtenido de http://www.scielo.org.co/pdf/inge/v19n2/v19n2a01.pdf

Pinto, F. (2020). Hechos ocurridos depues del periodo sobre el que se informa: Efectos Coronavirus. Revista Crecer Empresarial. Obtenido de https://journalusco.edu.co/index.php/cempresarial/article/view/2851/4001 